Article

\title{
Active Hybrid Solid State Transformer Based on Multi-Level Converter Using SiC MOSFET
}

\author{
Chun-gi Yun and Younghoon Cho * \\ Department of Electrical Engineering, Konkuk University, Seoul 05029, Korea; dbscnsrl@konkuk.ac.kr \\ * Correspondence: yhcho98@konkuk.ac.kr; Tel.: +82-10-6207-0431
}

Received: 18 November 2018; Accepted: 18 December 2018; Published: 26 December 2018

\begin{abstract}
As the types of loads have been diversified and demand has increased, conventional distribution transformers are difficult to maintain the constant voltage against voltage drop along with distance, grid voltage swell/sag, and various loads. Also, it is hard to control the power flow when connecting renewable energy sources. Active hybrid solid state transformer (AHSST) is application to keep the voltage and power quality. AHSST is a system that combines conventional distribution transformer and converter. Accordingly, it can be applied directly to distribution infrastructure and it has both the advantages of solid state transformer (SST) and conventional transformer. AHSST is capable of active voltage and current control and power factor control. It has a simpler structure than SST and it can perform the same performance with the lower rating converter. This paper presents two stage AHSST system based on multi-level converter. The converter is composed of the back-to-back converter using silicon carbide $(\mathrm{SiC})$ metal-oxide semiconductor field effect transistor (MOSFET). Proposed system has a wider voltage and power flow control range, lower filter size, and simpler control sequence than existing AHSST systems. The performance of the proposed system was verified by prototype system experiments.
\end{abstract}

Keywords: active hybrid solid-state-transformer; solid-state-transformer; multi-level converter; smart transformer

\section{Introduction}

Recently, as the micro grid is developed and the renewable energy source increases, it is difficult to maintain the stable power quality of the distribution grid. In addition, it is hard to keep the voltage and frequency quality constant due to voltage drop caused by the distribution distance. Thus, retaining a high quality of input and output voltage for variety loads is a new issue. The conventional distribution transformer has traditionally been used for distribution voltage conversion because of its simple structure, high reliability, and economic efficiency. However, this transformer has a passive operation characteristic. Thus, it affects the distribution grid if the load is varied. If voltage variation, such as the voltage sag or swell, occurs, these problems affect the output characteristics directly. To solve this problem, a tap transformer was used to adjust the winding by forming a tap on a part of the winding of the tap transformer. If the ratio of the turns of the tap transformer is $N: 1$ and the tap winding is $N_{\text {tap }}$, when the voltage sag occurs, the tap transformer turns ratio is converted to $N-N_{\text {tap }}: 1$ to increase the secondary side voltage. Conversely, when the voltage swell occurs, the winding ratio is reduced to $N+N_{\text {tap }}: 1$ to decrease the secondary side voltage. However, the tap transformer can only compensate for the certain voltage, so that the voltage compensation range is not linear. In addition, a mechanical tap changer is needed to physically change the tap winding. So, active and real-time control of variation in the distribution grid voltage is difficult.

Solid state transformers (SST) have been studied to overcome these drawbacks that are shown in Figure 1 [1-6]. SST is a system composed of power converter for micro grid, renewable energy 
source, and direct current (DC) distribution system. SST is capable of active control of primary side and secondary side voltage, current, power factor, and power flow. Real-time control of output voltage is also possible. Because SST uses high frequency transformer as electric isolation stage, they can have smaller volume and higher power density than the traditional power transformer. Nevertheless, SST has the disadvantage that the converter must be configured towards high voltage power semiconductor switches in order to cope with the high distribution grid voltage. Recently, high voltage rated power semiconductor switches over $15 \mathrm{kV}$ have been studied, but these are difficult to use commercially [7-10]. Therefore, in order to apply the commercial power semiconductor switches, cascaded multi-module structure in which power modules are connected in a series or parallel is forced. Accordingly, separate communication interface circuits are required for applying the cascaded multi-module structure and complicated control algorithms are needed to compensate the voltage and power unbalance between the modules [11-13]. Also, since the rectifiers stage of SST is connected in series without galvanic isolation, all of the modules must have high electrical insulation of several tens of $\mathrm{kV}$. DC link voltage, distribution grid voltage, and current sensor for controlling the system also require at least $20 \mathrm{kV}$ electrical isolation. In addition, since the SST completely replaces the existing transformer, it is necessary to construct a new infrastructure to employ it to the distribution grid. When a fault condition occurs in the SST, it is difficult to protect the load.

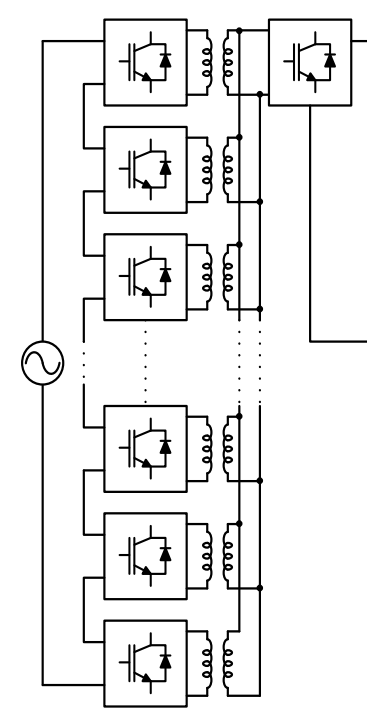

Figure 1. Solid state transformer.

Active hybrid solid state transformer (AHSST), as shown in Figure 2, has been researched to overcome these drawbacks [14-17]. AHSST is called a controllable network transformer, flexible transformer is a system which combines the conventional tap transformer and power converter that can perform the functions of SST. Input of the converter connected to part of the primary side winding of the tap transformer and the output of the converter is connected to the distribution grid in series. Unlike the conventional tap transformer, AHSST does not physically change the winding, but rather outputs the compensation voltage in series to the grid. AHSST has a simple structure and it can utilized directly to existing distribution infrastructure. AHSST can control the primary side and secondary side voltage, power factor, and power flow actively, according to the system structure. Real-time control is also possible, even with sudden variations in the distribution grid voltage such as voltage sag and swell. AHSST uses only a fraction of the distribution grid voltage as input, so it can operate with a lower voltage and power rating and lower electrical isolation than SST. In general, the input voltage of the AHSST is the tap voltage of the transformer, which is determined by the ratio of the tap winding to the primary side winding. Also, in the case of a distribution transformer, since the primary side voltage is very high and the current is very small as compared to the secondary side, so the power that AHSST has to handle is very small. Therefore, it can be applied to a distribution grid of several 
hundred kilowatt power class. AHSST has a structure in which a power converter is coupled to a conventional power transformer, which increases the weight of the transformer when compared to a conventional power transformer. However, since AHSST is rated only as part of the transformer, the volume is small and it can be attached to the cooling plate of the transformer, so that the volume of the entire system is minimized. In the previous studied AHSST, the converter can only output the average value of the tap voltage through pulse width modulation (PWM) switching, so that voltage synthesis is impossible when the tap voltage is zero. It is possible to output only the voltage in-phase with the tap voltage and the range of the output voltage can not exceed the tap voltage. So, it is impossible to cope with a voltage fluctuation, such as voltage sag or swell exceeding the tap winding ratio. In addition, both two tap voltage must be used to implement the boost and buck operation mode, which forces the use of high voltage rated power semiconductor switch. To solve these drawbacks, a structure in which two tap voltages are separately used has been studied. This structure uses two relays. Accordingly, this system has a disadvantage that a separate sequence is required to designate the relay operation point when the mode is change. Because AHSST is directly connected to the tap transformer, it is difficult to ensure control performance according to the internal impedance of the transformer. So, the dynamic response of the converter controller is important, because the input voltage and output power condition of the converter depend on the grid compensation voltage. In addition, since it is connected in series to the high voltage distribution grid, an analysis of the grid noise and electrical isolation are required. The basic structure AHSST is currently undergoing empirical studies. However, AHSST requires more research because the reliability of AHSST depends on the control algorithm, the circuit structure, and the electric and magnetic field characteristics of the transformer. System circuit stability also is needed. Nevertheless, since it has lower electric isolation and rating than the solid state transformer, it has an advantage in securing reliability when compared to conventional SST. The proposed AHSST can overcome all of these drawbacks. Since it has two stage structure, independent voltage output is possible depending on the polarity of the tap voltage and it has a wider voltage compensation range than the tap voltage. Therefore, even if only one tap voltage is used, the functional implementation is possible, so that no additional circuit, such as a relay, is required.

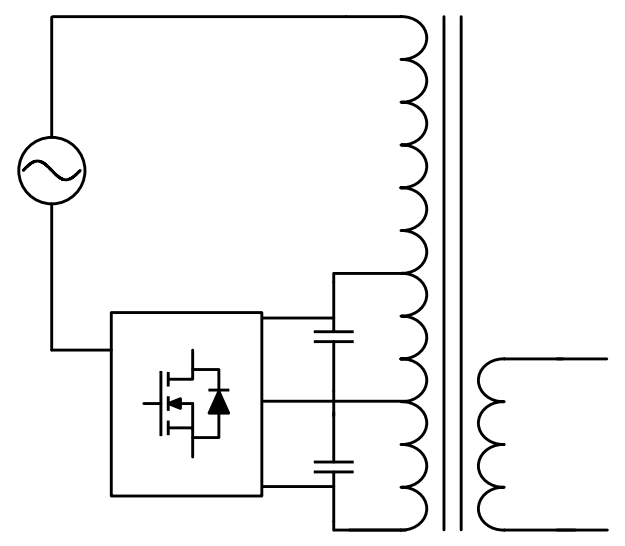

Figure 2. Active hybrid solid state transformer.

This paper presents novel two stage AHSST system that is based on three-level NPC converter using SiC MOSFET. The two stage AHSST structure has a wider control range, higher efficiency and power density, power factor, and power flow control range than previously studied AHSST system. The proposed system consists of two stage back-to-back converter composing of rectifier and inverter. Topologies of power stages employed three-level diode neutral point clamping (NPC) topology, so the power semiconductor switches with a voltage rating that is twice as low as a two-level topology can be used. Since, two stage structure has the DC link capacitors, the inverter can control the magnitude and phase angle of the output voltage independent to the tap voltage. Hence, it can operate for using only half of the tap voltage. All power semiconductor switches are applied with SiC MOSFETs and SiC 
schottky diodes to reduce the switching losses and to implement high efficiency and power density [7]. The design and implementation of power stage was verified through electrical insulation test and thermal simulation. In Section 2, the previously studied AHSST is analyzed and proposed AHSST system is designed and analyzed in Section 3. The performance of the proposed system is verified by prototype simulation and experiments in Sections 4 and 5.

\section{Active Hybrid Solid State Transformer}

AHSST consists of the tap transformer and power converter basically. The converter can be connected to the primary side or secondary side windings of the tap transformer, respectively. When the AHSST is connected to the secondary side windings, active control of the secondary side voltage and current and power factor control are possible. In this structure, since the converter takes the whole of the secondary side windings as input and output, the converter must cover the total power for the load. On the other hand, when the converter is connected to the parts of the primary side windings, active control of voltage, current, and power factor is also possible. The rating of the converter can be designed to be lower than the rating of the load. One stage AHSST structure that is studied in [14-18] consists of AC/AC converter that is shown in Figure 3. The AC/AC converter controls the magnitude of the output voltage that is average value of the tap voltage to control primary side voltage of the tap transformer. The secondary side voltage is finally controlled according to the controlled primary side voltage. $N_{p r i}, N_{t a p}$, and $N_{s e c}$ are primary side winding, tap winding, and secondary side winding, respectively.

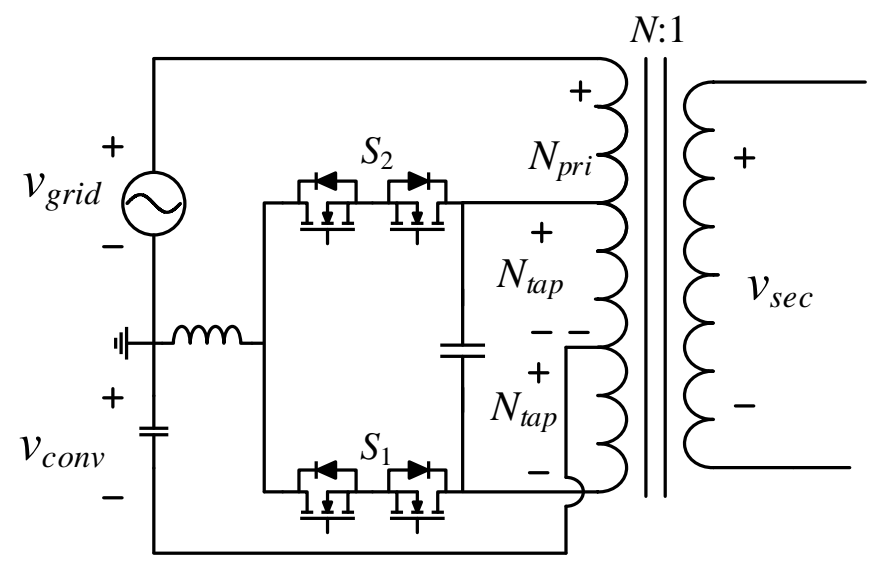

Figure 3. Circuit configuration of one stage active hybrid solid state transformer.

When $S_{2}$ is turned on, the turn ratio of transformer becomes $N_{p r i}-N_{t a p}: N_{s e c}$. So, the secondary side voltage increases. On the contrary, when $S_{1}$ is turned on, the turn ratio of the transformer becomes $N_{\text {pri }}+N_{\text {tap }}: N_{s e c}$. As the number of primary side winding increases, the secondary side voltage decreases. To control the secondary side voltage linearly, the output voltage of the converter compensated the distribution grid in series through the complementary PWM operation of $S_{1}$ and $S_{2}$. The output voltage of the converter according to the state of the switches is given by the following Equations (1) and (2). $V_{\text {grid }}, V_{\text {pri }}, V_{\text {tap }}, D, V_{\text {conv }}$, and $T_{S}$ are the grid voltage, primary side voltage, tap voltage, duty of the $S_{2}$, output voltage of converter, and switching period, respectively.

$$
\begin{aligned}
& 0<\mathrm{t}<D: V_{\text {conv }}=V_{\text {tap }}, V_{\text {pri }}=V_{\text {grid }}+V_{\text {conv }} \\
& D<\mathrm{t}<T_{s}: V_{\text {conv }}=-V_{\text {tap }}, V_{\text {pri }}=V_{\text {grid }}-V_{\text {conv }} \\
& -V_{\text {tap }}<V_{\text {conv }}<V_{\text {tap }} \\
& -\frac{\left(N_{p r i}+N_{t a p}\right)}{N_{p r i}}<V_{s e c}(\text { p.u })<\frac{\left(N_{p r i}+N_{t a p}\right)}{N_{p r i}}
\end{aligned}
$$


The maximum output voltage of the converter is shown in Equation (3). It can not exceed the tap voltage. Accordingly, the control range of secondary side voltage is equal to the tap winding ratio shown in Equation (4). In addition, the AC/AC converter does not have separate energy storage components, such as capacitors, so it cannot synthesize the output voltage when the tap voltage is zero. As a result, the $\mathrm{AC} / \mathrm{AC}$ converter controls the output voltage magnitude easily within a certain range, but the phase of the output voltage can not control because only the in-phase voltage can be synthesized at all times. For this reason, it is very difficult to control the power factor in the one stage AHSST. Using dual virtual quadrature sources (DVQS) algorithm, which is a method of controlling power flow by injecting second order harmonics into the duty reference of the converter and change the phase of secondary side voltage $[15,16]$, power factor and power flow control is possible, but its control range is limited by the load and the line impedance conditions. Since the voltage of the $2 N_{\text {tap }}$ is used as an input of converter, the voltage applied to the switch, becomes $2 N_{t a p}$ so that the use of a high-voltage switch is forced. To overcome this disadvantage, a structure shown in Figure 4 has been studied in which each $N_{\text {tap }}$ are used independently [18].

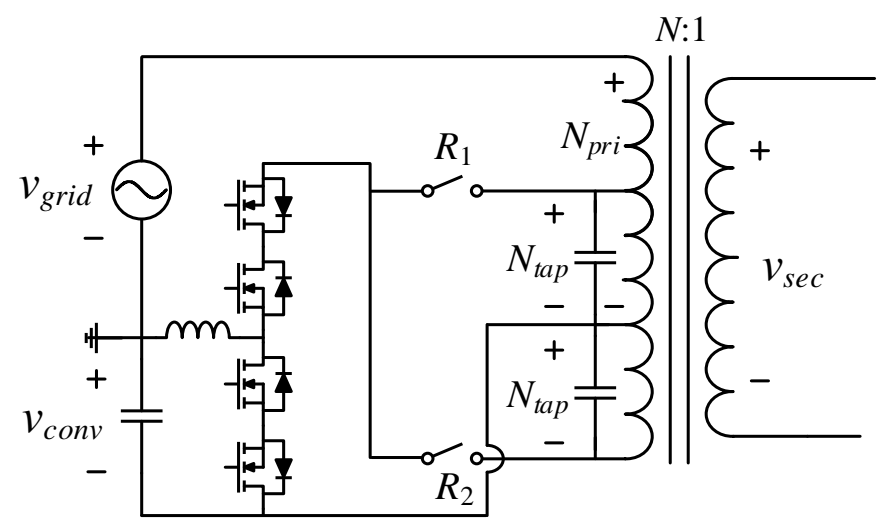

Figure 4. Circuit configuration of improved one stage active hybrid solid state transformer.

This system structure is also composed of an AC/AC converter, but relays are added to select each tap voltage respectively according to boost or buck operation mode. If $R_{1}$ is turned on, then it operates in the boost mode and only uses the upper tap voltage. At this mode, the converter outputs an in-phase voltage to the grid. Accordingly, primary side voltage is increased so that the secondary side voltage is also increased. On the contrary, when $R_{2}$ is turned on, lower tap voltage is only used. It operates in the buck mode and input voltage of the converter is $-D V_{\text {tap }}$. So, converter only outputs the inverse-phase voltage to the grid. As a result, primary side voltage is decreased so that secondary side voltage is also decreased. Because the system using relays only uses half the tap voltage, it can reduce the voltage applied to the power semiconductor switch by half when compared with the system that is shown in the Figure 3. However, the reliability of the system is not ensured by using relays, and the control sequence for changing the operation mode is required.

The novel two stage AHSST is proposed in this paper. The power converter consists of an AC/DC rectifier and DC/AC inverter. The compensation range of the secondary side voltage can be widened according to the rectifier boost ratio. The inverter can output independent voltage, regardless of the phase of the tap voltage, because of the energy storage components, such as DC link capacitors, so it can control the power factor easily. The range of the power factor and power flow control is also wider than the conventional AHSST system in Figures 3 and 4. Two stage AHSST can be operated with a simple control algorithm and no mode change sequence is required. Additionally, it is possible to synthesize the voltage using only one tap voltage. 


\section{Proposed Active Hybrid Solid State Transformer}

\subsection{Topology}

The proposed AHSST system is shown in Figure 5. Two stage back-to-back converter is applied instead of one stage AC/AC converter and each stage is designed by three-level NPC topology. Two stage back-to-back converter consists of AC/DC rectifier and DC/AC inverter. $V_{\text {pri }}, V_{\text {grid }}, V_{\text {inv }}$, and $V_{s e c}$ are the primary side voltage, grid voltage, inverter output voltage, and secondary side voltage respectively. The output voltage of the inverter $\left(V_{i n v}\right)$ is connected in series to the grid to control the primary side voltage $\left(V_{p r i}\right)$, and thereby controls the secondary side voltage $\left(V_{s e c}\right)$ of the tap transformer. Unlike the existing AHSST system, because there is the DC link between stages, the inverter can output the voltage independent to the magnitude and phase of the tap voltage. Consequently, the inverter can freely adjust the magnitude and phase of the output voltage and current and it is possible to control both the primary side and the secondary side power factor of the transformer. Control of power flow is also possible when renewable energy sources are connected. Due to the characteristics of the transformer, the phase angle of the tap voltage and the secondary side voltage are the same as the phase angle of the primary side voltage. The phase angle of the grid voltage that is needed for power factor correction (PFC) control of the rectifier can be measured only by the tap voltage instead of the high distribution grid voltage. Accordingly, the lower electrical isolation is required for the voltage and current sensors.

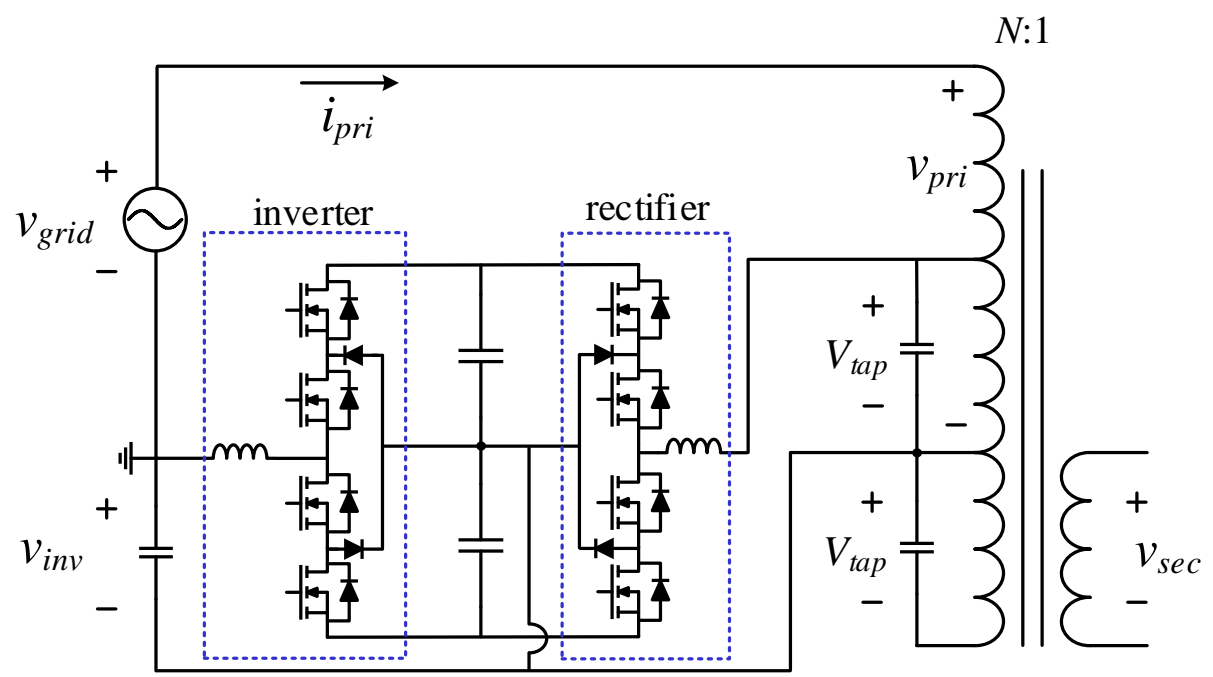

Figure 5. Circuit configuration of proposed two stage active hybrid solid state transformer.

The rectifier controls the DC link voltage and input current with PFC control. The rectifier performs a role of synthesizing a constant DC link voltage, regardless of the grid voltage variation. By controlling the DC link voltage, the output voltage range of the inverter is maintained, even when the grid voltage sag or swell occurs. The inverter controls the output voltage that compensated the grid in series. Since the secondary side voltage is determined by sum of the grid voltage and output voltage of the inverter, secondary side voltage, and power flow control are implemented by controlling the magnitude and the phase of the output voltage of the inverter. The relation of the primary side voltage and the inverter output voltage are shown in Equation (5). Unlike the existing AHSST, there is no separate sequence for operation mode. The inverter measures the secondary side voltage and controls it constantly at the rated value. Since the polarity of the output voltage is automatically determined by the controller as the grid voltage variation, the inverter voltage controller outputs the voltage reference to maintain the secondary side voltage constantly. Since there are DC link capacitors, the voltage of the inverter can be output, regardless of the polarity of the tap voltage, so no separate sequence is required. When grid voltage sag occurs, the primary side voltage and the secondary side 
voltage are lowered, so that the inverter outputs a positive voltage error. Thus, the in-phase voltage with the grid is synthesized and compensated in series with the grid, resulting in an increase in the secondary side voltage. Conversely, when grid voltage swell occurs, the primary side voltage and secondary side voltage are increase. At this time, the inverter outputs a negative voltage error, and therefore synthesizes the inverse-phase voltage with the grid and compensates it into the grid. As a result, secondary side voltage is decreased.

$$
\begin{gathered}
V_{p r i}=V_{g r i d}+V_{i n v} \\
V_{s e c}=\frac{V_{p r i}}{N}=\frac{V_{g r i d}+V_{i n v}}{N}
\end{gathered}
$$

If the transformer turn ratio is $N: 1$, then the secondary side voltage is equal to Equation (6) and the range of the compensable secondary side voltage is $V_{i n v} / N$. The magnitude of the inverter duty reference, DC link voltage, and output voltage of the inverter are $D_{r e f i n v}$ and $V_{D C}, V_{i n v}$ are given by Equation (7). As a result, $D_{\text {ref_inv }}$ of the inverter for controlling the $V_{s e c}$ is finally summarized as in Equations (8), (9) and (10). The turn ratio of the tap transformer and DC link voltage are constant, regardless of grid voltage variation. Accordingly, the $D_{\text {ref_inv }}$ is determined by $V_{\text {grid }}$ and reference of the $V_{s e c}$ and control reference of the secondary side voltage.

$$
\begin{gathered}
V_{i n v}=D_{\text {ref_inv }} V_{D C} \\
V_{s e c}=\frac{V_{p r i}}{N}=\frac{V_{\text {grid }}+\left(D_{r e f \_i n v} V_{D C}\right)}{N} \\
V_{\text {grid }}=N V_{s e c}-D_{\text {ref_inv }} V_{D C} \\
D_{\text {ref_inv }}=\frac{N V_{\text {sec }}-V_{\text {grid }}}{V_{D C}}
\end{gathered}
$$

Since the maximum value of the inverter output voltage magnitude is determined by $V_{D C}$, the range of the secondary side voltage can be increased when compared to the conventional AHSST by increasing the boost ratio of the rectifier. In the case of the Republic of Korea, the distribution grid voltage is line-to-neutral $13.2 \mathrm{kV}$, and the tap winding ratio of the distribution tap transformer is $5 \%$ normally. The conventional AHSSTs shown in Figure 3 use two tap voltage $\left(2 V_{\text {tap }}\right)$ as the input, and the maximum voltage applied to the switch is $1866 \mathrm{~V}$ in this case. For this reason, there is a disadvantage that the use of a high voltage switch of $2000 \mathrm{~V}$ or more is compulsory. However, in the proposed AHSST, rectifier synthesizes the boosted DC voltage as compared to the peak value of the tap voltage, so that inverter can output the rating voltage using only one of tap voltage $\left(V_{\text {tap }}\right)$. Therefore, the secondary side voltage control range may be wider than the tap winding ratio depending on the boost ratio of the rectifier. Compared with Figure 4 which selectively uses only one of the tap, the proposed AHSST can remove the relays and operate with a simple control algorithm without the separate mode change sequence. In the proposed AHSST, the boost ratio of the rectifier is selected to be 2.35 times when considering the modulation index (MI), so that the DC link voltage is designed to be $2200 \mathrm{~V}$. Also, three-level NPC topology is applied to the rectifier and inverter, so that the voltage applied to the switch is reduced to $1100 \mathrm{~V}$ when compared to the conventional AHSST system. Therefore, $1200 \mathrm{~V}$ or $1700 \mathrm{~V}$ MOSFET can be used. The AHSST system shall have insulation for the noise from the distribution grid and must be robust against temperature since it is directly connected to the transformer. For this reason, all power semiconductor switches are designed to have high efficiency and power density by applying SiC MOSFET with low switching loss and high speed switching. 


\subsection{Control Algorithm}

Figure 6 shows the control structure of the proposed system. The rectifier and inverter have its own independent controllers. $G_{V C_{-} r e c}, G_{C C_{-} r e c}$, and $G_{V C_{-} i n v}$ are voltage controller of rectifier, current controller of rectifier, and voltage controller of inverter, respectively. The rectifier controls the DC link voltage and input current. The current controller performs PFC so that controls the current in-phase to the tap voltage, regardless of the phase of the inverter output voltage. DC link voltage controller controls the constant DC link voltage to maintaining the control range of the inverter. The rectifier controller consists of the inner input current controller and the outer DC link voltage controller, and the proportional-integral (PI) and proportional-resonant (PR) controller are employed, respectively. The output of the voltage controller is multiplied by the phase angle measured from the PLL to obtain the current reference. The input current of the rectifier is regulated by the current controller. The power factor of the rectifier is close to the unity. If the voltage unbalance of between each DC link voltages occurs, then DC offset voltage is generated in the inverter output voltage and current. This DC offset voltage may cause a saturation effect of the core of tap transformer. To prevent this problem, DC link voltage balance controller should be added. Calculated difference of the DC link voltage is compensated to the rectifier duty reference to eliminate the DC offset. Since the secondary side voltage contains the ratio of both grid voltage and inverter output voltage, the inverter configures the voltage controller based on the secondary side voltage. The inverter voltage controller uses PR controller and it is designed to obtain the highest gain at the grid frequency band. The duty reference is converted to the PWM signal through the modulator and is applied to each power semiconductor switch $[19,20]$.

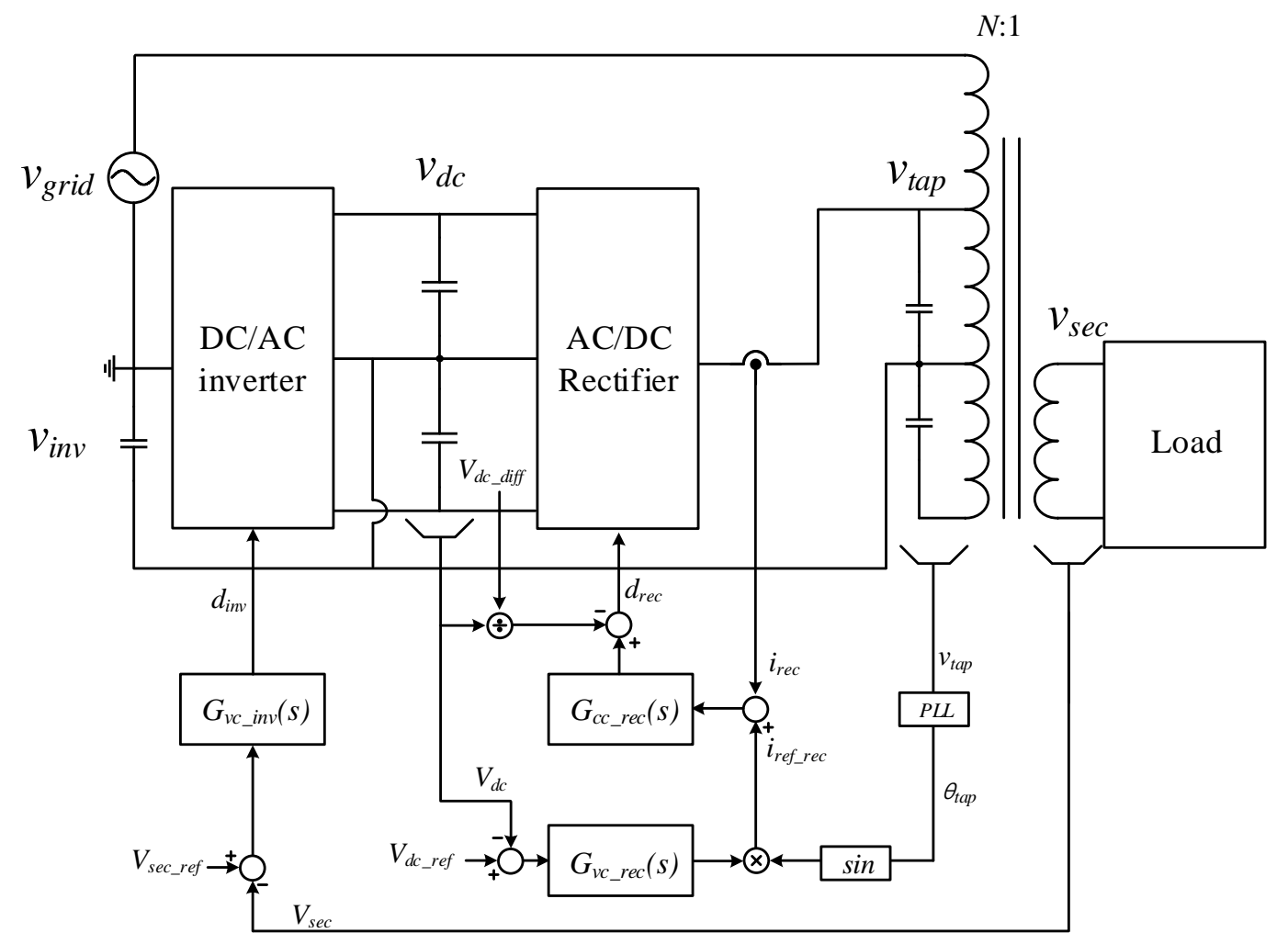

Figure 6. Control structure of proposed two stage active hybrid solid state transformer.

\subsection{Power Stage Design}

Half bridge three-level NPC topology is employed for both the rectifier and the inverter. The power stage is designed as a single board with the rectifier and the inverter for high power density. Figure 7a shows a design diagram of the power board. The power semiconductor switch uses $1200 \mathrm{~V} \mathrm{SiC}$ and $1200 \mathrm{~V} \mathrm{SiC} \mathrm{schottky} \mathrm{diode} \mathrm{for} \mathrm{lower} \mathrm{switching} \mathrm{losses} \mathrm{and} \mathrm{high} \mathrm{efficiency.} \mathrm{In} \mathrm{order} \mathrm{to}$ 
ensure the robustness and electrical insulation of power stage against the noise from the grid, $8 \mathrm{~mm}$ air holes are inserted between each switch and the snubber capacitors and terminals. Figure $7 \mathrm{~b}$ shows the simulation results under the condition of input power of $500 \mathrm{~W} / 660 \mathrm{~V}$. The final total AHSST system is rated at $10 \mathrm{~kW} / 13.2 \mathrm{kV}$ and the power converter has a $5 \%$ of transformer voltage and power rating. The operating condition is $5 \%$ and voltage compensation is under $5 \%$ voltage sag. At this time, the output current of the inverter $0.75 \mathrm{~A}$. Although the system simulation and the experiment were performed by 20 times of scale down, the rating of the designed AHSST was ultimately designed to correspond to $13.2 \mathrm{kV}$, and thermal analysis and insulation tests were performed under the above condition. The simulation result in Figure $7 \mathrm{~b}$ shows the thermal analysis of the power stage with 30 min operation and natural cooling condition under rated load. The ambient temperature is given as 20 degrees celsius, maximum temperature is measured 34.4 degrees celsius.

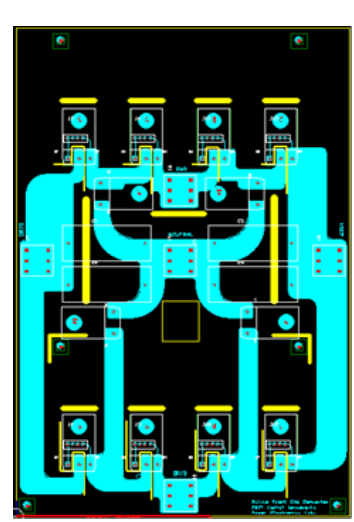

(a)

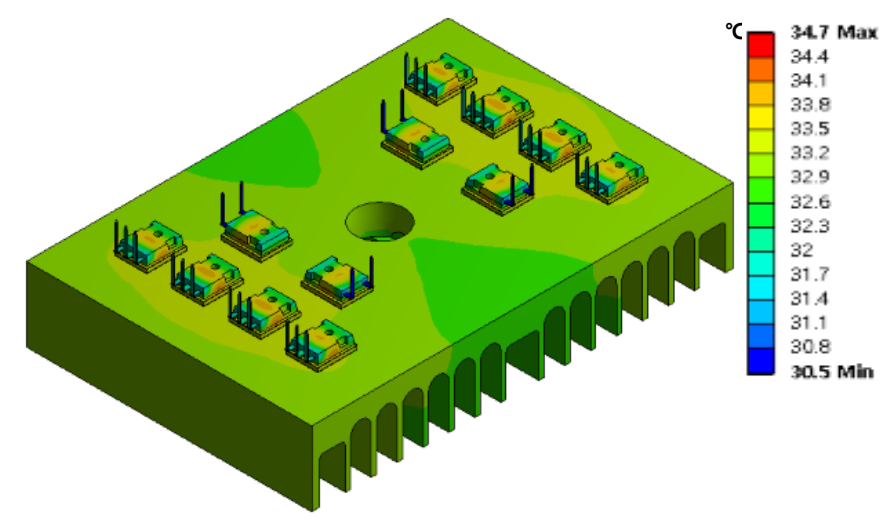

(b)

Figure 7. Power stage of proposed active hybrid solid state transformer (AHSST). (a) Power board diagram; and, (b) Thermal simulation results.

\section{Simulation Results}

To examine the performance of the proposed system, the simulation model that is shown in Figure 6 is implemented using PowerSiM 11.1. Table 1 gives the prototype system parameters. Tap transformer has $660 \mathrm{~V}: 220 \mathrm{~V}$ voltage rating.

Table 1. Parameters for the simulation.

\begin{tabular}{ccc}
\hline Power Stage & Parameters & Values \\
\hline \multirow{4}{*}{ Tap transformer } & Turn ratio of winding & $3: 1$ \\
& Voltage ratio & $660: 220 \mathrm{~V}$ \\
& Tap winding ratio & $10 \%$ \\
& Power rating $P_{\text {out }}$ & $1 \mathrm{~kW}$ \\
\hline \multirow{3}{*}{ Rectifier } & Input voltage $V_{\text {tap }}$ & $66 \mathrm{~V}$ \\
& Output voltage $V_{D C}$ & $220 \mathrm{~V}$ \\
& Filter inductance $L_{r e c}$ & $4 \mathrm{mH}$ \\
& DC link capacitance $V_{D C}$ & $250 \mu \mathrm{F}$ \\
& Switching frequency $f_{\text {sw_rec }}$ & $20 \mathrm{kHz}$ \\
\hline \multirow{2}{*}{ Inverter } & Output voltage $V_{\text {niv }}$ & $33 \mathrm{~V}$ \\
& Filter inductance $L_{i n v}$ & $1 \mathrm{mH}$ \\
& Switching frequency $f_{\text {sw_inv }}$ & $20 \mathrm{kHz}$ \\
\hline
\end{tabular}

The tap voltage was selected to be $66 \mathrm{~V}$, which is $10 \%$ of grid voltage. The DC link voltage of the rectifier is designed to $220 \mathrm{~V}$ when considering MI. The voltage compensation range of the inverter is $\pm \frac{110}{\sqrt{2}} \mathrm{~V}$, which is $11 \%$ of grid voltage. The system power rating is $1 \mathrm{~kW}$ (resistor load) and switching frequency is $20 \mathrm{kHz}$. At this time, the voltage applied to the switch is $110 \mathrm{~V}$, which can be reduced by 
$41 \%$ from the conventional AHSST structure under the same condition. Simulation is tested under the two following cases.

- Case 1. Boost and buck mode operation

Case 1 is a condition for controlling the secondary side voltage when the grid voltage is constant. At this time, the maximum range of the secondary voltage that can be controlled by the inverter is $\pm \frac{1}{N V_{i n v}}$ V. Figure 8 shows waveforms of the input pole voltage $\left(V_{a n_{-} r e c}\right)$, input current $\left(i_{L_{-} r e c}\right)$, and duty reference $\left(D_{\text {ref_rec }}\right)$ of the rectifier. $V_{\text {an_ref }}$ consists of three levels of voltage $\left(0, \pm V_{D C} / 2\right)$ and the phase of the input current is close to the unity. Since the grid voltage is constant, the rectifier outputs the same voltage waveform in both the boost and buck mode operations, regardless of the inverter output. The input current of the rectifier is determined by the magnitude of the output compensation voltage of the inverter.

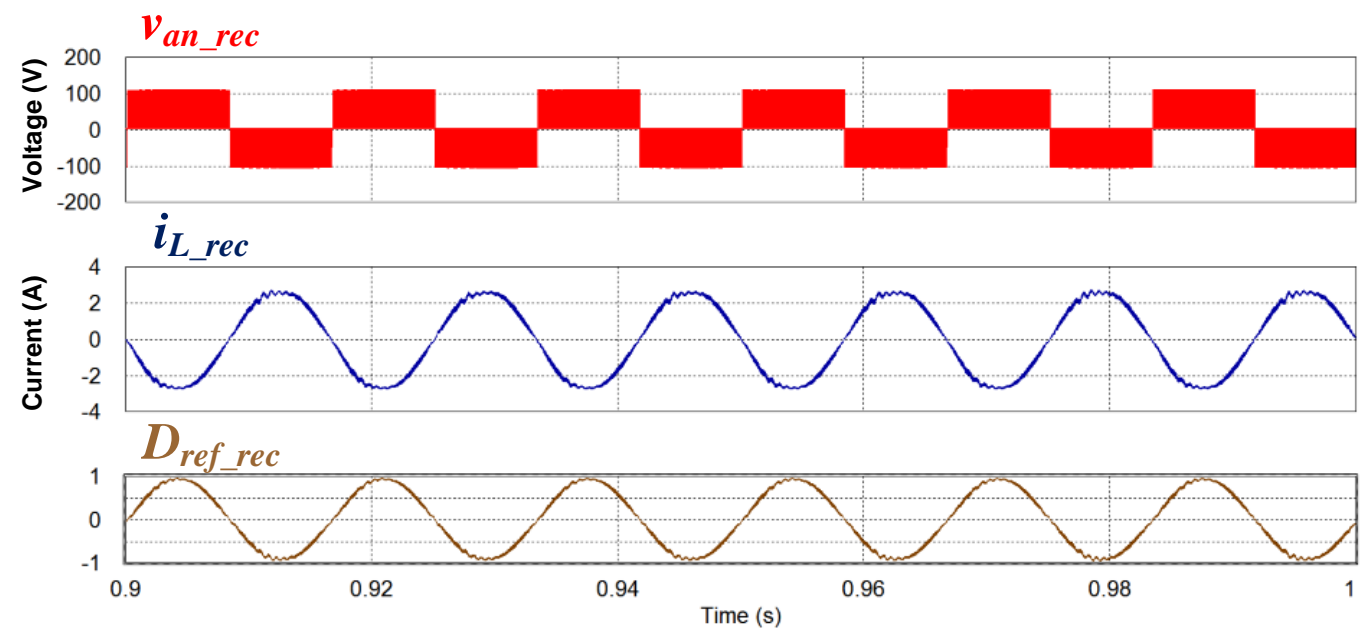

Figure 8. Simulation results of the rectifier.

Figure 9 shows the waveform of the grid voltage $\left(V_{\text {grid }}\right)$, inverter output voltage $\left(V_{\text {inv }}\right)$, tap voltage $\left(V_{\text {tap }}\right)$, and secondary side voltage $\left(V_{\text {sec }}\right)$ under buck mode operation. When buck mode is started after $1 \mathrm{~s}$, the inverter outputs the inverse phase voltage as the tap voltage. Since the DC link voltage is controlled to $220 \mathrm{~V}$ by the rectifier, the maximum voltage of the inverter output voltage is $-76 \mathrm{~V}$ by the Equation (7), so that it is greater than the tap voltage of $66 \mathrm{~V}$. Therefore, the voltage control range of the inverter is $15 \%$ wider than the existing AHSST. As a result, the magnitude of secondary side voltage becomes $194 \mathrm{~V}$, according to Equation (6).

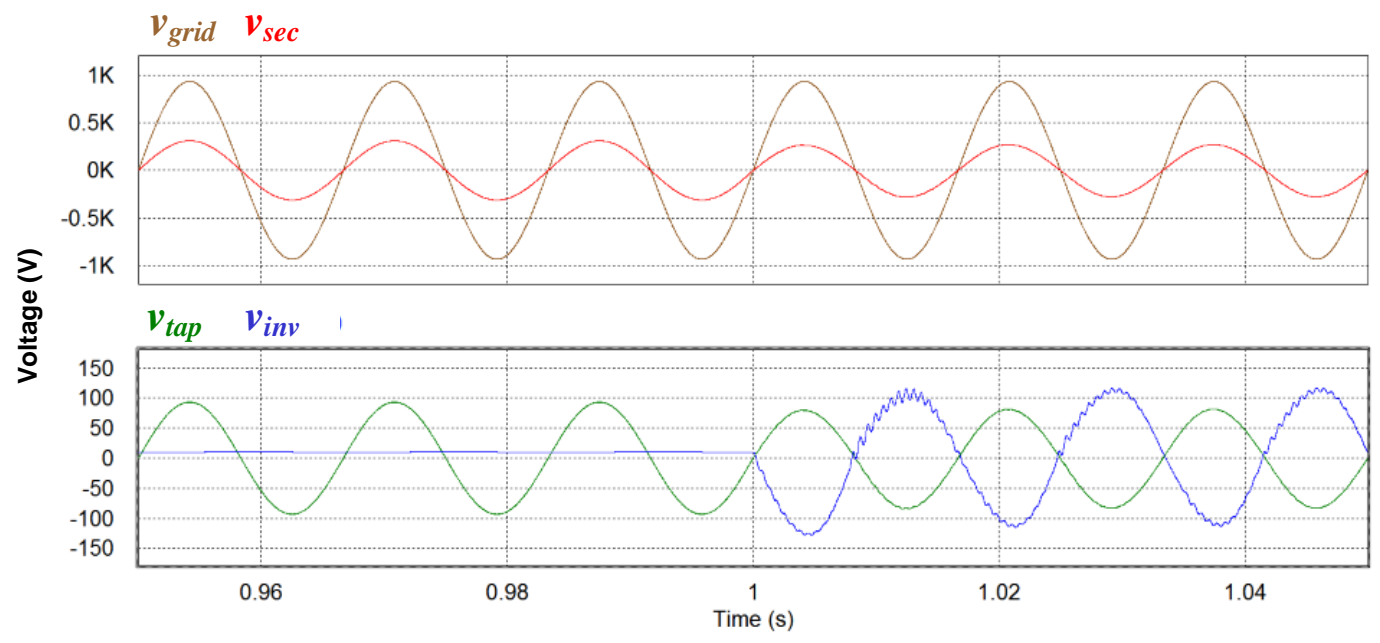

Figure 9. Simulation results of buck mode operation. 
Figure 10 is waveform under boost mode operation. When boost mode is started after $1 \mathrm{~s}$, the inverter synthesizes the voltage of the same phase as the grid voltage. Output voltage of the inverter is $76 \mathrm{~V}$, so that magnitude of secondary side voltage becomes $245 \mathrm{~V}$, according to Equation (6).

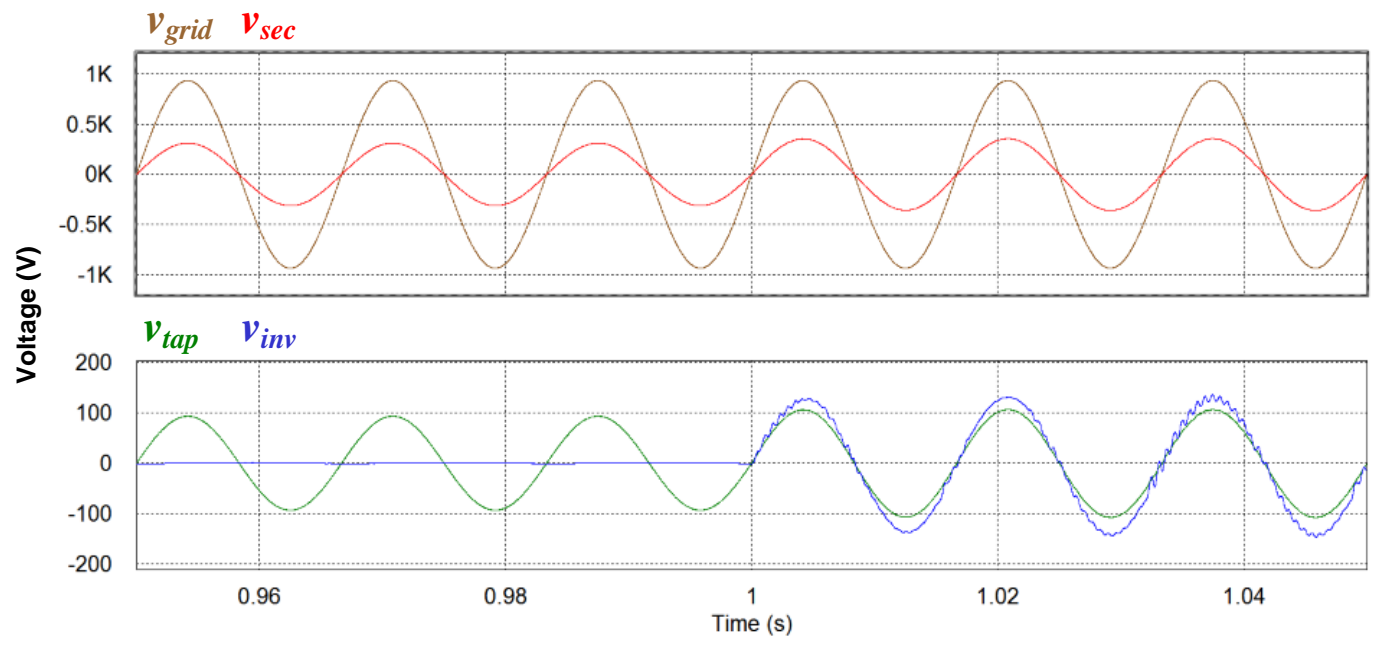

Figure 10. Simulation results of boost mode operation.

In the case 1 condition, the voltage control range of the secondary side is $\pm 25 \mathrm{~V}$, which is $3 \mathrm{~V}$ wider than the existing AHSST, which can control the secondary side voltage to $\pm 22 \mathrm{~V}$. The compensation voltage range can be further increased by increasing the boost ratio of the rectifier.

- Case 2. Constant control of secondary side voltage under the grid voltage sag and swell occurs

Case 2 is the constant control of secondary side voltage when $10 \%$ grid voltage sag or swell occurs. The primary side voltage must be kept constant for constant secondary side voltage, even when grid voltage changes. Figure 11 shows the waveform in the case 2 condition. If a voltage sag occurs after $0.5 \mathrm{~s}$, a positive inverter output voltage reference is generated to boost the decreased secondary side voltage. Conversely, if a voltage swell occurs after $1 \mathrm{~s}$, inverter outputs a negative voltage reference to decrease the secondary side voltage.

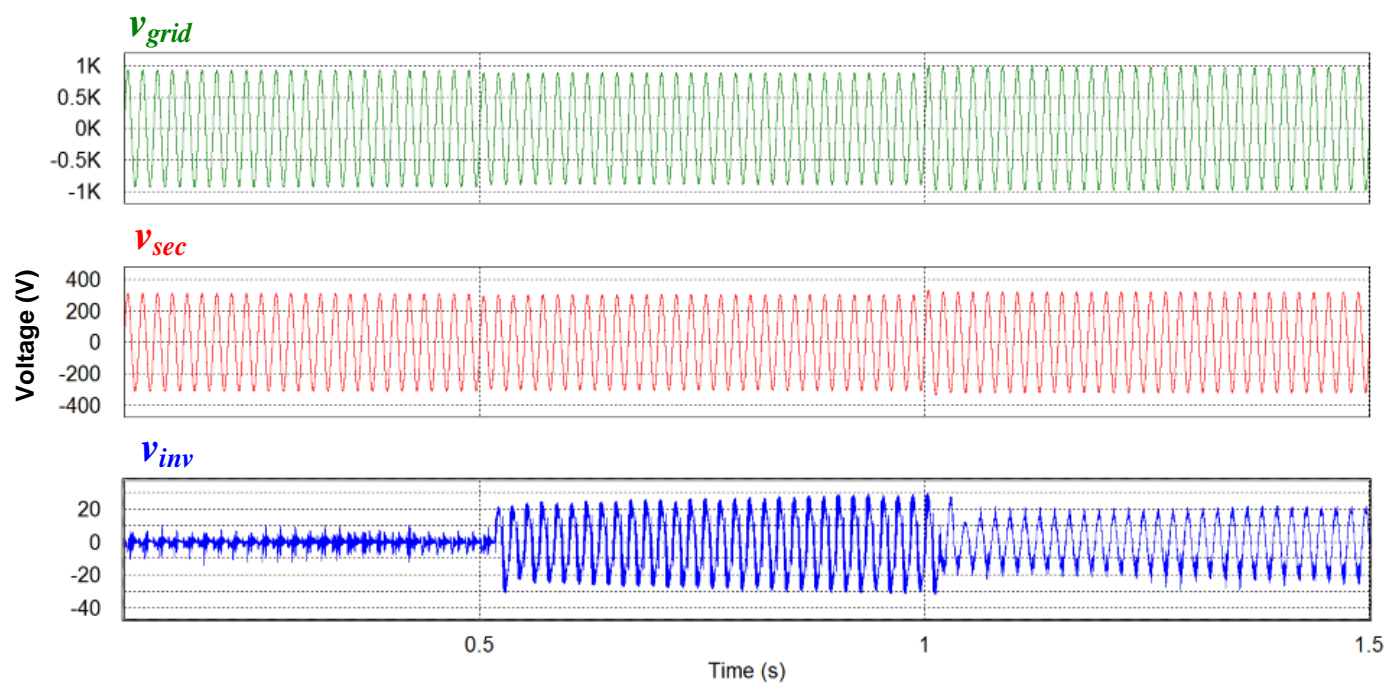

Figure 11. Simulation results of constant voltage control of secondary side.

\section{Experimental Results}

Figure 12 shows the experimental setup for the proposed system prototype. The same parameters that are shown in Table 1 are applied. 1:6 transformer and variable AC autotransformer (variac) were 
used to obtain grid voltage of $660 \mathrm{~V}$. The input voltage of the system is regulated by connecting the 1:6 transformer to variac.

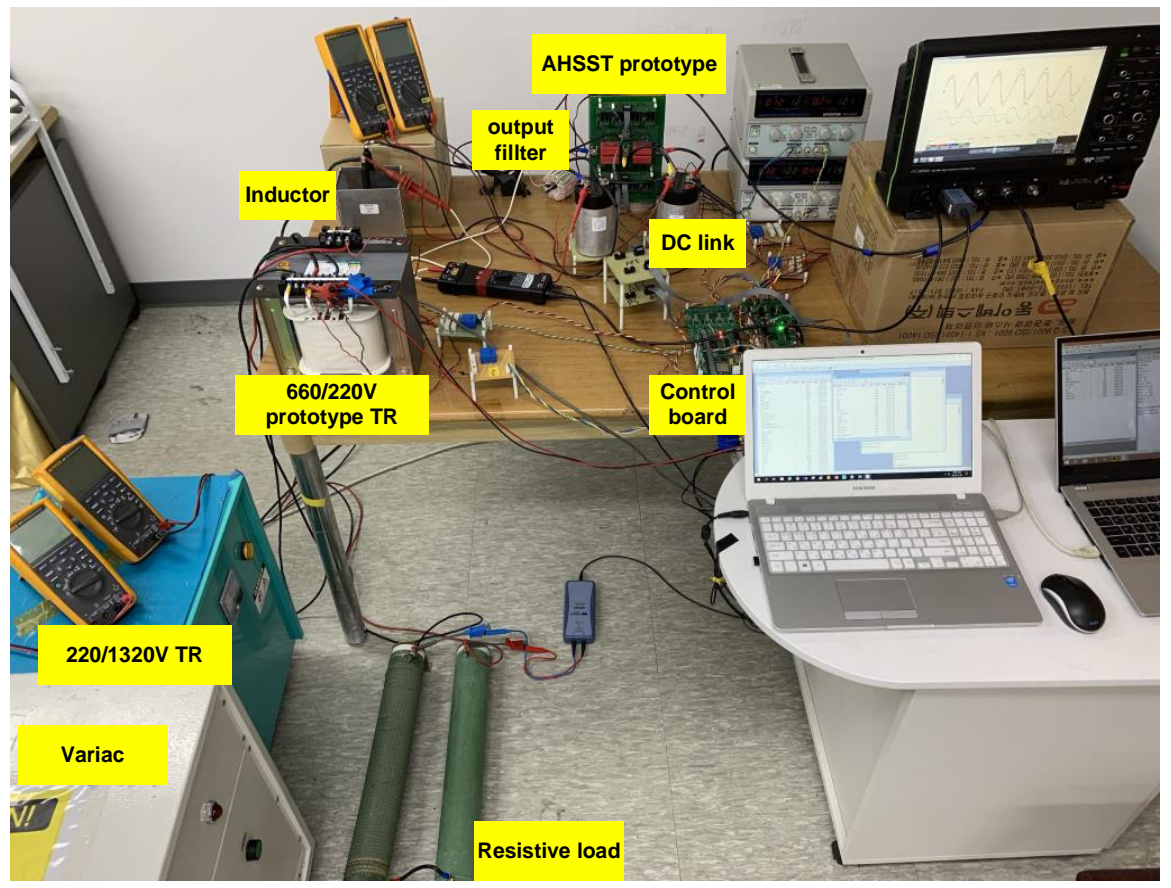

Figure 12. Experimental setup.

The power semiconductor switches and diodes in each power stage used $1200 \mathrm{~V} \mathrm{SiC} \mathrm{MOSFET}$ (C2M0040120) and 1200 V SiC schottky diode (C4D20120D). By using SiC devices, higher switching frequency was applied rather than conventional commercial Si devices, reducing the filter volume and increasing the efficiency and power density. Experiments were also performed on two cases, as in the simulations. All experimental results were carried out under $1 \mathrm{~kW}$ resistive load conditions.

Figure 13 shows waveforms of input pole voltage, input current and duty reference of rectifier in case 1 condition. Power factor of rectifier input voltage and current is close to the unity. The DC link voltage is maintained at $220 \mathrm{~V}$.

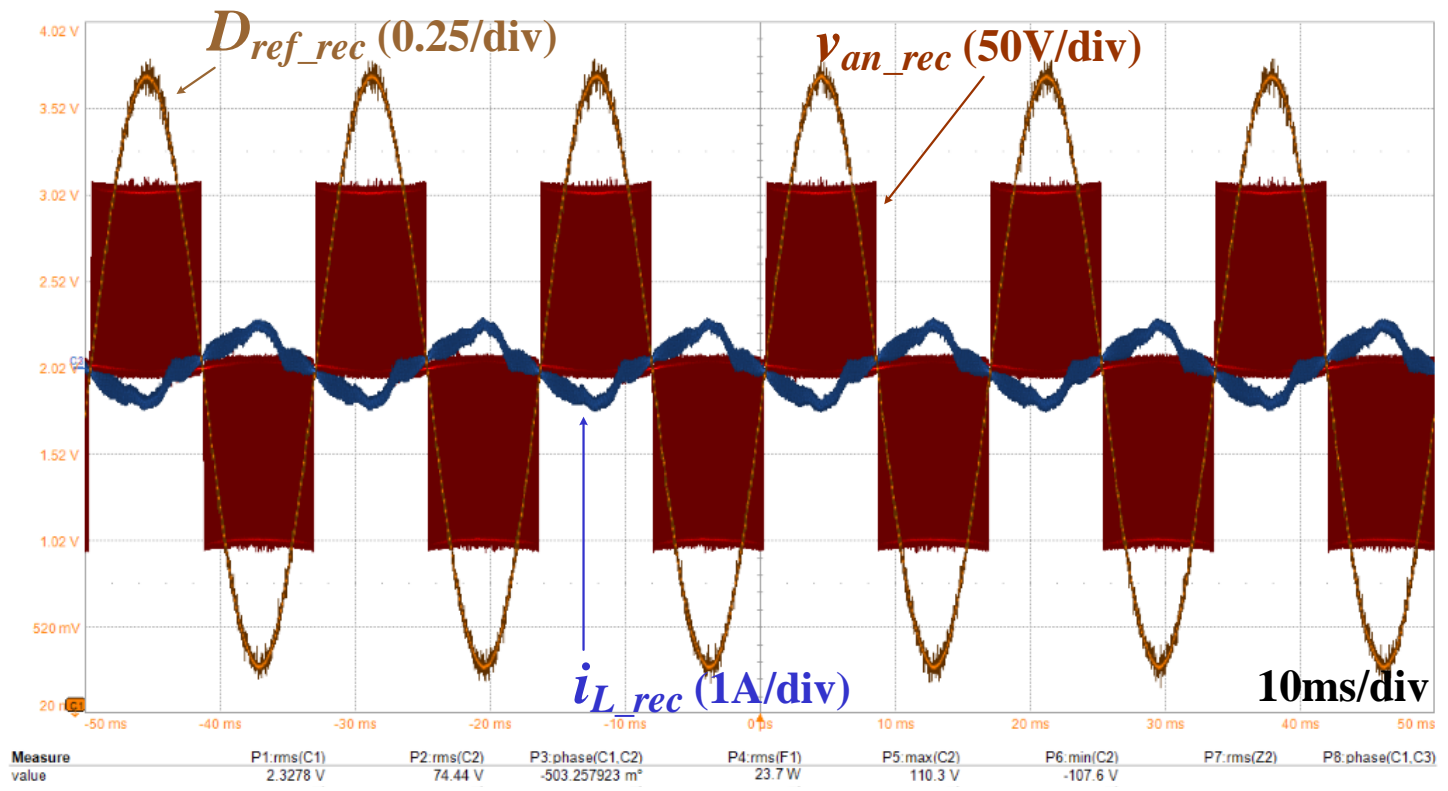

Figure 13. The input voltage, current and duty reference of the rectifier. 
Figure 14 shows waveforms of $V_{\text {grid }}, V_{\text {sec }}, V_{\text {inv }}$, and $V_{\text {tap }}$. After $50 \mathrm{~ms}$, when buck mode is started after $50 \mathrm{~ms}$, the primary side and secondary side voltage decreased. The output voltage of the inverter was $-76 \mathrm{~V}$, so that primary side voltage of the transformer is controlled from $660 \mathrm{~V}$ to $584 \mathrm{~V}$. As the result, secondary side voltage is controlled to $194 \mathrm{~V}(0.88 \mathrm{p} . \mathrm{u})$, according to Equation (6). The control range of the inverter and secondary side voltage range is $15 \%$ wider than existing AHSST.

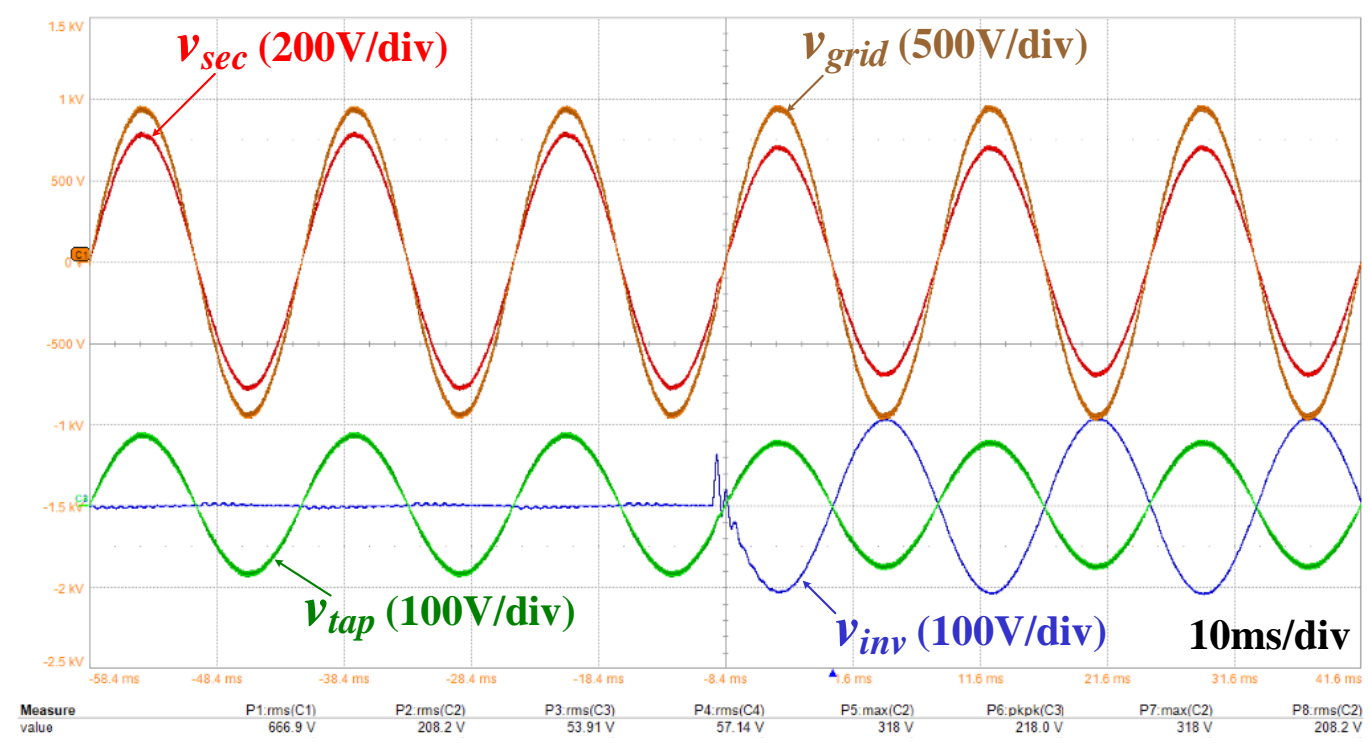

Figure 14. The grid, secondary side, inverter voltage and grid current at the buck mode operation.

Figure 15 shows the experimental results of boost operation mode. After $50 \mathrm{~ms}$, boost mode is started, so that primary side and secondary side voltage is increased. The output voltage of the inverter is $76 \mathrm{~V}$. The primary side voltage is controlled from $660 \mathrm{~V}$ to $736 \mathrm{~V}$ and the secondary side voltage is increased to $245 \mathrm{~V}$ (1.11 p.u).

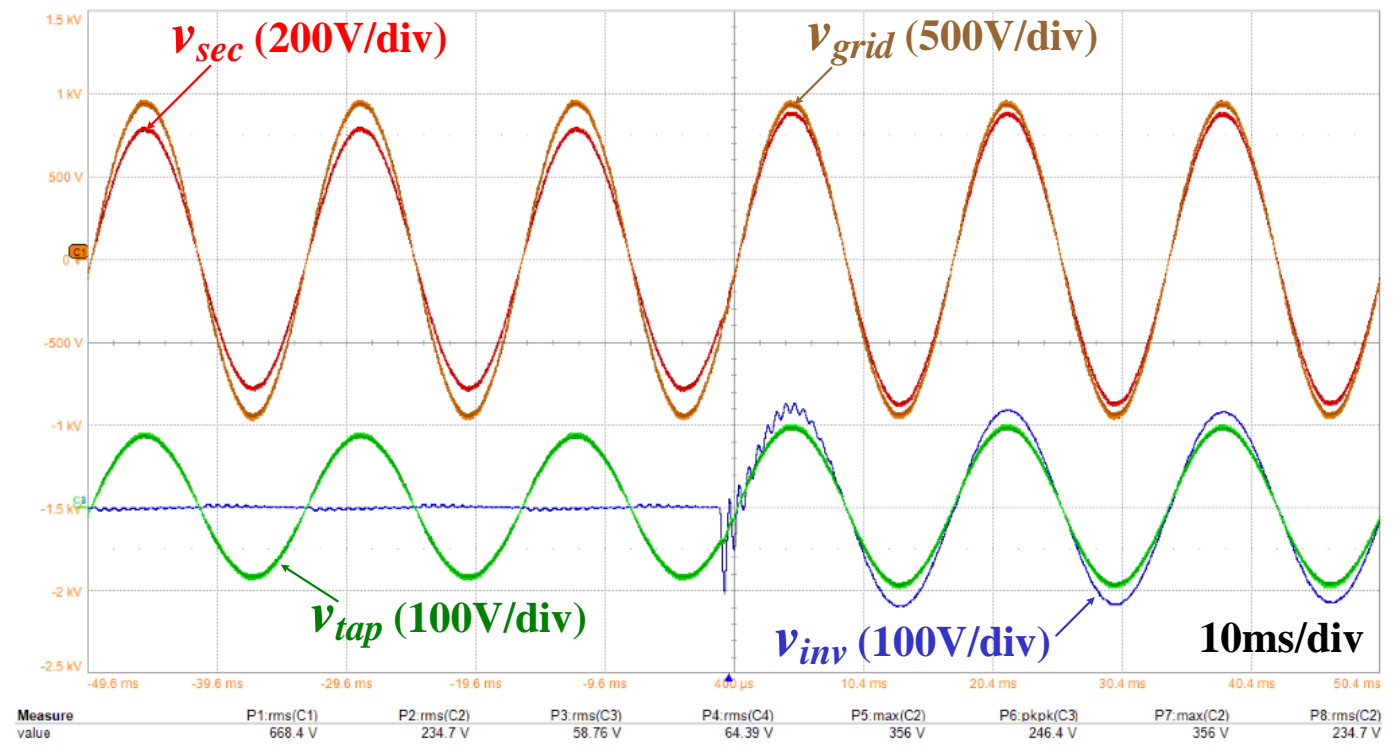

Figure 15. The grid, secondary side, inverter voltage, and grid current at the operation mode change.

Figure 16 shows the results of case 2 . After $6 \mathrm{~s}$, grid voltage sag occurs and the inverter outputs the in-phase compensation voltage. After $14 \mathrm{~s}$, grid voltage swell occurs and inverter outputs the reverse-phase compensation voltage. Maximum secondary side voltage regulation is less than $0.4 \%$ $(1 \mathrm{~V})$. 


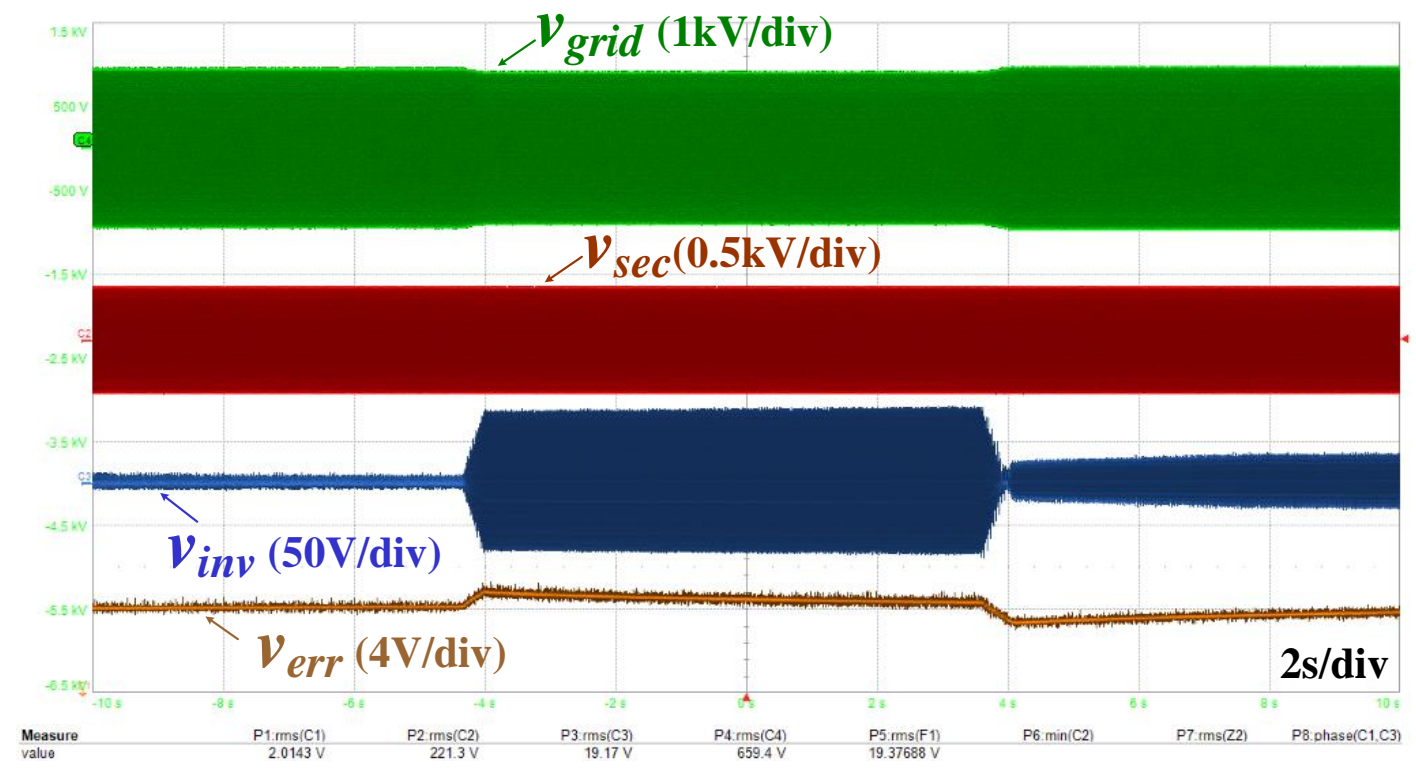

Figure 16. The grid, secondary side, inverter voltage and voltage error under the case 2 condition.

\section{Conclusions}

This paper describes the novel two stage AHSST based on multi-level converter. The proposed AHSST has the wider voltage compensation range and power factor control performance as compared to the existing AHSST and has been verified by simulations and experiments. In the experiments of case 1 condition, it was confirmed that the inverter output voltage in the boost and buck modes are $\pm 76 \mathrm{~V}$, respectively, which is $15 \%$ higher than the maximum compensation voltage range of the existing AHSST. In addition, since the inverter can synthesize the independent output voltage to the grid, the same performance can be utilized only half of the tap winding. The control algorithm of the proposed AHSST is simple to implement. Thus, stable constant voltage control of secondary side is possible without separate control sequence. Also, by the experiments of case 2 condition, it is confirmed that the proposed system has good performance to grid voltage variation. Secondary side voltage regulation under $5 \%$ voltage sag and swell condition is less than $0.4 \%(1 \mathrm{~V})$. As a result, if voltage sag or swell occur irregularly in the grid, or if there is a voltage drop across the distance, instantaneous compensation is possible and stable voltage and power quality can be maintained.

Author Contributions: C.Y. proposed system structure and performed the system implementation and experiments. Y.C. managed the paper.

Funding: This research was funded by Korea Electric Power Corporation(KEPCO) (Grant number ${ }^{3}:$ R18XA06-61) and "Human Resources Program in Energy Technology" of the Korea Institute of Energy Technology Evaluation and Planning (KETEP), granted financial resource from the Ministry of Trade, Industry \& Energy, Republic of Korea. (No. 20174030201660).

Acknowledgments: This research was supported by Korea Electric Power Corporation(KEPCO) (Grant number ${ }^{3}$ : R18XA06-61) and "Human Resources Program in Energy Technology" of the Korea Institute of Energy Technology Evaluation and Planning (KETEP), granted financial resource from the Ministry of Trade, Industry \& Energy, Republic of Korea. (No. 20174030201660).

Conflicts of Interest: The authors declare no conflict with interest.

\section{References}

1. She, X.; Yu, X.; Wang, F.; Huang, A.Q. Design and demonstration of a 3.6-kV-120-V/10-kVA solid-state transformer for smart grid application. IEEE Trans. Power Electron. 2014, 29, 3982-3996. [CrossRef]

2. Jih-Sheng, L.; Maitra, A.; Mansoor, A.; Goodman, F. Multilevel intelligent universal transformer for medium voltage applications. In Proceedings of the Fourtieth IAS Annual Meeting, Hong Kong, China, 2-6 October 2005; Volume 1893, pp. 1893-1899. 
3. She, X.; Huang, A.Q.; Burgos, R. Review of Solid-State Transformer Technologies and Their Application in Power Distribution Systems. IEEE J. Emerg. Sel. Top. Power Electron. 2013, 1, 186-198. [CrossRef]

4. Lai, J.S.; Maitra, A.; Goodman, F. Performance of a distribution intelligent universal transformer under source and load disturbances. In Proceedings of the Conference Record of the 2006 IEEE Industry Applications Conference Forty-First IAS Annual Meeting, Tampa, FL, USA, 8-12 October 2006; pp. 719-725.

5. Zjang, J.; Wang, Z.; Shao, S. A three-phase modular multilevel DC-DC converter for power electronic transformer applications. IEEE J. Emerg. Sel. Top. Power Electron. 2017, 5, 140-150.

6. Wang, X.; Liu, J.; Ouyang, S.; Xu, T.; Meng, F.; Song, S. Control and experiment of an h-bridge-based three-phase three-stage modular power electronic transformer. IEEE Trans. Power Electron. 2016, 31, 2002-2011. [CrossRef]

7. Madhusoodhanan, S.; Tripathi, A.; Patel, D.; Mainali, K.; Kadavelugu, A.; Hazra, S.; Bhattacharya, S.; Hatua, K. Solid-State Transformer and MV Grid Tie Applications Enabled by 15 kV SiC IGBTs and $10 \mathrm{kV} \mathrm{SiC}$ MOSFETs Based Multilevel Converters. IEEE Trans. Ind. App. 2015, 51, 3343-3360. [CrossRef]

8. Huang, A.Q.; Zhu, Q.; Wang, L.; Zhang, L. 15 kV SiC MOSFET: An enabling technology for medium voltage solid state transformers. CPSS Trans. Power Electron. Appl. 2017, 2, 118-130. [CrossRef]

9. Madhusoodhanan, S.; Mainali, K.; Tripathi, A.; Patel, D.; Kadavelugu, A.; Bhattacharya, S.; Hatua, K. Harmonic Analysis and Controller Design of $15 \mathrm{kV}$ SiC IGBT-Based Medium-Voltage Grid-Connected Three-Phase Three-Level NPC Converter. IEEE Trans. Power Electron. 2017, 32, 3355-3369. [CrossRef]

10. Lai, J.S.; Lai, W.H.; Moon, S.R.; Zhang, L.; Maitra, A. A 15-kV class intelligent universal transformer for utility applications. In Proceedings of the 2016 IEEE Applied Power Electronics Conference and Exposition (APEC), Long Beach, CA, USA, 20-24 March 2016; pp. 1974-1981.

11. Shi, J.; Gou, W.; Yuan, H.; Zhao, T.; Huang, A.Q. Research on voltage and power balance control for cascaded modular solid-state transformer. IEEE Trans. Power Electron. 2011, 26, 1154-1166. [CrossRef]

12. Liu, J.; Yang, J.; Zhang, J.; Nan, Z.; Zheng, Q. Voltage balance control based on dual active bridge DC/DC converters in a power electronic traction transformer. IEEE Trans. Power Electron. 2018, 33, 1696-1714. [CrossRef]

13. Wang, J.; Gu, B.; Duan, Q.; Ma, C.; Ji, B.; You, J. Control strategy of solid state power electronic transformer under voltage disturbance conditions. In Proceedings of the IECON 2015-41st Annual Conference of the IEEE Industrial Electronics Society, Yokohama, Japan, 9-12 November 2015; pp. 003081-003085.

14. Das, D.; Kandula, R.P.; Muñoz, J.A.; Divan, D.; Harley, R.G.; Schatz, J.E. An Integrated Controllable Network Transformer-Hybrid Active Filter System. IEEE Trans. Ind. Appl. 2015, 51, 1692-1701. [CrossRef]

15. Divan, D.; Sastry, J. Controllable Network Transformers. In Proceedings of the 2008 IEEE Power Electronics Specialists Conference, Rhodes, Greece, 15-19 June 2008; pp. 2340-2345.

16. Das, D.; Divan, D.M.; Harley, R.G. Power flow control in networks using controllable network transformers. IEEE Trans. Power Electron. 2010, 25, 1753-1760. [CrossRef]

17. Chen, H.; Kandula, R.P.; Prasai, A.; Schatz, J.; Divan, D. Flexible transformers for distribution grid control. In Proceedings of the 2016 IEEE Energy Conversion Congress and Exposition (ECCE), Milwaukee, WI, USA, 18-22 September 2016; pp. 1-6.

18. Kandula, R.P.; Chen, H.; Prasai, A.; Lambert, F.; Schatz, J.; Divan, D. Field upgradeable transformer: A fractionally-rated voltage regulator for the distribution system. In Proceedings of the 2016 IEEE Energy Conversion Congress and Exposition (ECCE), Milwaukee, WI, USA, 18-22 September 2016; pp. 1-8.

19. Choudhury, A.; Pillay, P.; Williamson, S.S. A performance comparison study of space-vector and carrier-based pwm techniques for a 3-level neutral point clamped (NPC) traction inverter drive. In Proceedings of the 2014 IEEE International Conference on Power Electronics, Drives and Energy Systems (PEDES), Mumbai, India, 16-19 December 2014.

20. Ojha, A.; Chaturvedi, P.; Littal, A.; Jain, S. Carrier based common mode voltage reduction techniques in neutral point clamped inverter based ac-dc-ac drive system. J. Power Electron. 2016, 16, 142-152. [CrossRef]

(C) 2018 by the authors. Licensee MDPI, Basel, Switzerland. This article is an open access article distributed under the terms and conditions of the Creative Commons Attribution (CC BY) license (http:/ / creativecommons.org/licenses/by/4.0/). 